\title{
Obtaining of Astaxanthin from Crab Exosqueletons and Shrimp Head Shells
}

\author{
Jorge Montiel Montoya 1, Salvador Velazco Mata 2, José Luis Acosta 1, Braulio Edgar \\ Herrera Cabrera 3(i), Luis Germán López Valdez 4(i), César Reyes 5(i), Hebert Jair \\ Barrales Cureño ${ }^{6, *}$ (D)
}

1 Centro Interdisciplinario de Investigación para el Desarrollo Integral Regional, Instituto Politécnico Nacional Unidad Sinaloa, Boulevard Juan de Dios Bátiz 250, Col. San Joachín, Guasave, Sinaloa, México; mont54@ yahoo.com (J.M.M.); 2 Industries VEPINSA SA de CV. Los Mochis, Sinaloa, Mexico; velazco.mata@gmail.com (S.V.M);

3 Colegio de Postgraduados, Campus Puebla. Boulevard Forjadores No 205 Santiago Momoxpan, Puebla. C.P. 72760; behc@colpos.mx (B.E.H.C.);

4 Laboratorio de Productos Naturales, Área de Química. AP74 Oficina de correos Chapingo, Universidad Autónoma Chapingo, Km 38.5 Carretera México-Texcoco, 56230, Texcoco, Estado de México, México; lgermanlv@ taurus.chapingo.mx (L.G.L.V.);

5 Universidad Intercultural del Estado de Puebla, Calle Principal a Lipuntahuaca S/N, 73475, Puebla, México; cesar.reyes@uiep.edu.mx (C.R.);

6 Instituto de Investigaciones Químico Biológicas, Universidad Michoacana de San Nicolás de Hidalgo, Edificio B-3, Ciudad Universitaria, 58030, Morelia, Michoacán, México; hebert.jair@ uiep.edu.mx (H.J.B.C.);

* Correspondence: hebert.jair@uiep.edu.mx

Received: 9.01.2021; Revised: 5.02.2021; Accepted: 8.02.2021; Published: 13.02.2021

Abstract: Fresh wastes of Mexican headshell shrimp (Litopenaeus vannamei), blue crab (Callinectes bellicosus), and Mexican brown crab (Callinectes sapidus) exoskeletons were autoclaved, dried, and grounded at a particle size of $150 \mu \mathrm{m}$. Macerated samples were diluted to ethyl acetate, acetone, cyclohexane, isopropyl alcohol, hexane, heptane, and a combination of hexane-acetone-ethanol-toluene solvents. High-Performance Liquid Chromatography analysis determined the astaxanthin amount in every organic solvent extract. Acetone was the most efficient solvent: $114 \mu \mathrm{g} / \mathrm{g}$ (L. vannamei), $39 \mu \mathrm{g} / \mathrm{g}$ (C. bellicosus), and $44 \mu \mathrm{g} / \mathrm{g}$ (C. sapidus); the mixture of hexane-acetone-ethanol-toluene resulted a idoneus solvent when was used on crab exoskeletons: $39 \mu \mathrm{g} / \mathrm{g}$ (C. bellicosus) and $51 \mu \mathrm{g} / \mathrm{g}$ (C. sapidus). The astaxanthin characterization was performed without saponification, in $L$. vannamei chromatograms, the amount of trans astaxanthin was $6.23 \mu \mathrm{g} / \mathrm{g}(5.47 \%$ of total area), in C. bellicosus was $26.13 \mu \mathrm{g} / \mathrm{g}$ (67\% of total area) and in C. sapidus was $28.42 \mu \mathrm{g} / \mathrm{g}$ (64.6\% of total area).

Keywords: acetone extract; HPLC analysis; saponification.

(C) 2021 by the authors. This article is an open-access article distributed under the terms and conditions of the Creative Commons Attribution (CC BY) license (https://creativecommons.org/licenses/by/4.0/).

\section{Introduction}

Mexico is an important source of crustaceans. It is attained through fishing and aquaculture; Mexico's shrimp production was around 224 thousand tons, more recently, FAO (2020) reported for Mexico a total annual crab production of 51 thousand tons [1]. In Mexico, there are not installed processing plants that could take advantage of such waste products and, therefore, represent a high business opportunity. It is important to mention that crabs exoskeletons and shrimp shells can be used as a raw material to recover products of high added value such as chitin, chitosan, glucosamine, and astaxanthin [2-4]. Astaxanthin belongs to the xanthophyll chemical family; these are oxygenated compounds derived from carotenoids [5]. Carotenoids presented an orange-red appearance and are commonly used as a pigment of 
salmon meat, trout, crustaceans, and poultry meat [6]. Some of the works reported that astaxanthin showed the highest biological activity with respect to other carotenoids [7]. The Food and Drug Administration of the United States (USFDA) has been approved the use of astaxanthin as a colorant in animal feed and fish food [8]; also, the European Commission considers the astaxanthin as a food colorant (Roche, 1987) [8]. Today, astaxanthin has gained special strength cause of its different applications in several industries, mainly as a food supplement agent in human and animal feed, as well as the pigment collection sources such as crab and shrimp [9]. Several methods to extract astaxanthin include fermentative process extraction and not fermentative extraction method from crab wastes combined with organic solvents, enzymatic methods, extraction with plant or marine oil sources, and supercritical fluids $[10,11]$. However, the most used method for astaxanthin extraction is organic solvents, among them alcohol and ethyl acetate, isopropanol and/or acetone, ethanol, and methanol nhexane, and isopropyl alcohol [12]. Besides, the yield astaxanthin determination is a key factor in choosing the astaxanthin extraction method; one of the most used is the spectrophotometry determination and HPLC method [13]. The last technique is a rapid and accurate method that allows establishing a quality control, specifically by the presence of esters, where the most common chemical structure is: free form, monoester, and diester. To avoid its chemical behavior is necessary to remove the astaxanthin esters' fatty acid chains by alkaline saponification or enzymolysis, then only after this, HPLC can easily separate astaxanthin isomers. Identification esters can be determined by High-Performance Liquid Chromatography-Mass Spectrometry (HPLC-MS) [14]. Therefore, in this work, we used HPLC as a standard method to quantify and identify astaxanthin main esters and isomers obtained from shrimp headshells, blue crab, and brown crab, a common waste on the northwest coasts of Mexico. The main purpose of the current research is to propose a sustainable method to extract astaxanthin from shrimp (Litopenaeus vannamei), headshells, blue crabs (Callinectes sapidus), and brown crabs (Callinectes bellicosus) exoskeletons. It means the most common Mexican crustaceans produced by aquaculture or fishing. For this, we proposed a solvent extraction method of fresh exoskeletons by using an autoclave oven and grounded by mean a manual mill to obtain a size particle of $150 \mathrm{~mm}$. Later, a powder sample of L. vannamei, $C$. sapidus, and $C$. bellicosus was exposed to a common organic solvent (ethyl acetate, acetone, cyclohexane, isopropyl alcohol, hexane, heptane, ethanol, and the mix hexane-acetone-ethanoltoluene: HAET). Finally, the HPLC method determined the amount of astaxanthin to quantify and determine the type of astaxanthin molecules extracted.

\section{Materials and Methods}

\subsection{Chemicals and reagents.}

Analitical solvents (Sigma Aldrich, USA) used were acetone (100\% purity), absolute ethanol (99.5\% purity), ethyl acetate ( $99.5 \%$ purity), hexane $(99.5 \%$ purity), toluene $(99.3 \%$ purity), cyclohexane (99.3\% purity), heptane (99\% purity), isopropyl alcohol (70\% in water). The HAET mixture (hexane-acetone-ethanol-toluene) was prepared in a relationship of 10:7:6:7 mL. 
2.2. Demineralization and sample powder obtention from Mexican shrimp head shells and exoskeleton of blue crab and brown crab.

$14 \mathrm{~kg}$ of fresh shrimp head, $5 \mathrm{~kg}$ of a fresh shell of blue, and $5 \mathrm{~kg}$ of brown crab were washed with distilled water and autoclaved (Market Forge Model STM-E) at $121^{\circ} \mathrm{C}$ during 15 $\min$ at $15 \mathrm{lb} \mathrm{in}^{2}$ of pressure. When the system achieved $100^{\circ} \mathrm{C}$ of temperature, the pressure was lowered at $0.5 \mathrm{lb} \mathrm{in}^{2}$ during $10 \mathrm{~min}$. The sample was withdrawn, dried in the shade for $12 \mathrm{~h}$, and then dehydrated in an oven at $50{ }^{\circ} \mathrm{C}$ for two hours (Yamato DX 302 oven). The dried sample was grounded in a manual meat mill No. 32 (SKU: MC-32) and sieved (No. 40 mesh) to obtain a particle size of $150 \mu \mathrm{m}$.

\subsection{Astaxanthin extraction from Mexican shrimp and crab exoskeleton.}

$30.0 \mathrm{mg}$ of powder sample was placed in a volumetric flask of $100 \mathrm{~mL}$. Then it was added $100 \mathrm{~mL}$ of every reagent organic solvent proved in this investigation (ethyl acetate, acetone, cyclohexane, isopropyl alcohol, hexane, heptane, ethanol, and the mix hexaneacetone-ethanol-toluene HAET (Sigma Aldrich, USA), and the mixture was treated in an ultrasound device (Cole Parmer Model 0889021) during one minute. Then, the volumetric flasks were filled with hexane (Sigma Aldrich, USA) up to the mark. Every solution of the solvents prepared was taken $10 \mathrm{~mL}$ and were added $5 \mathrm{~mL}$ of acetone at $100 \%$ of purity and gradually filled since up $50 \mathrm{~mL}$ and the final solution were well manually mixed.

\subsection{Sample saponification.}

We used a protocol reported previously by $\mathrm{Hu}$ et al. (2019); the method consisted of adding $4 \% \mathrm{KOH}$-ethanol solution to every $5 \mathrm{~mL}$ of sample to adjusted $\mathrm{pH}$ to 10.0 . The sample was saponified for 5 minutes. Finally, the sample was filtered before to inject into the HPLC.

\subsection{Molecular mass astaxanthin determination.}

The seven solvents' astaxanthin hydrolysis capacity was estimated with a precolumn packed with silica (maxil silica column of 5 nanometers $4.0 \times 5.0 \mathrm{~mm}$ ), using a conventional Varian 9050 HPLC system with a UV detector at a wavelength of $472 \mathrm{~nm}$. The mobile phase consisted of 75-25 hexane-ethyl acetate at $23{ }^{\circ} \mathrm{C}$; flow rate of $2.5 \mathrm{~mL}$ min-1 and isocratic pressure of 85 psi (Isoocratic pump Varian 9002). The columns were calibrated by a standard calibration method using astaxanthin and its isomers as standards of molecular mass (Sigma Aldrich, $596.84 \mathrm{~g} / \mathrm{mol}$ ). Hydrosilate samples of every solvent were filtered by using $0.22 \mu \mathrm{m}$ Millipore membrane to remove excessive debris. A volume of $20 \mu \mathrm{L}$ was injected into HPLC by a syringe. The astaxanthin concentration was determined by extrapolating the absorbance values using a standard curve.

\subsection{Statistical analysis.}

Statistical analysis was performed through the program SAS (2018), chromatographic dates were analyzed using the multiple means comparison test (ANOVA, P <0.05). 


\section{Results and Discussion}

\subsection{Astaxanthin quantification.}

HPLC method was used to quantify astaxanthin extracted with organic solvents proved in this work. Table 1 shows the results. It is evident that with acetone, the highest astaxanthin yields; in non saponified shrimp samples (L. vannamei), it was yielded $114 \mu \mathrm{g} / \mathrm{g}$ and with saponified samples was quantified $92 \mu \mathrm{g} / \mathrm{g}$ (Table 1). In shrimp, the second solvent was isopropyl alcohol with $99 \mu \mathrm{g} / \mathrm{g}$ in unsaponified samples and $92 \mu \mathrm{g} / \mathrm{g}$ on saponified samples; complete results are shown in Table 1 . In the case of astaxanthin extracted from blue $(C$. sapidus) and brown crab (C. bellicosus) exoskeletons, the best solvents were acetone and the mix HAET.

Table 1. Asthaxanthin extracted from shrimp powder (L. vannamei) quantified by HPLC.

\begin{tabular}{l|l|l|l|l} 
Solvent & $\boldsymbol{\mu g} / \mathbf{g}$ & $\mathbf{S D}$ & $\boldsymbol{\mu g} / \mathbf{g}$ & $\mathbf{S}$ \\
\hline & $\begin{array}{l}\text { Astaxanthin } \\
\text { without } \\
\text { saponification }\end{array}$ & $\boldsymbol{\mu g} \mathbf{g}^{-\mathbf{1}}$ & $\begin{array}{l}\text { Astaxanthin } \\
\text { saponification }\end{array}$ & $\boldsymbol{\mu g ~}^{-\mathbf{1}}$ \\
\hline Ethyl acetate & $68 \mathrm{~d}$ & \pm 0.3 & $65 \mathrm{~b}$ & \pm 0.1 \\
\hline Acetone & $114 \mathrm{a}^{1}$ & \pm 0.4 & $92 \mathrm{a}$ & \pm 0.2 \\
\hline Cyclohexane & $81 \mathrm{c}$ & \pm 0.5 & $60 \mathrm{~b}$ & \pm 0.5 \\
\hline HAET & $83 \mathrm{c}$ & \pm 0.1 & $53 \mathrm{c}$ & \pm 0.4 \\
\hline Isopropyl alcohol & $99 \mathrm{~b}$ & \pm 0.15 & $92 \mathrm{a}^{*}$ & \pm 0.3 \\
\hline Hexane & $83 \mathrm{c}$ & \pm 0.2 & $38 \mathrm{e}$ & \pm 0.1 \\
\hline Heptane & $80 \mathrm{c}$ & \pm 0.2 & $47 \mathrm{~d}$ & \pm 0.5 \\
\hline Ethanol & $86 \mathrm{c}$ & \pm 0.3 & $66 \mathrm{~b}$ & \pm 0.4
\end{tabular}

${ }^{1} \mathrm{p}<0.05$ Significant differences; SD standard deviation of three trials.

With acetone were quantified $39 \mu \mathrm{g} / \mathrm{g}$ (C. sapidus) and $44 \mu \mathrm{g} / \mathrm{g}$ (C. bellicosus), while with the mix HAET was obtained $39 \mu \mathrm{g} / \mathrm{g}$ (C. sapidus) and $51 \mu \mathrm{g} / \mathrm{g}$ (C. bellicosus), respectively; complete results are showed in Table 2.

Table 2. Astaxanthin extracted from crab powder exoskeletons quantified by HPLC.

\begin{tabular}{|c|c|c|c|c|}
\hline Solvent & $\mu \mathrm{g} / \mathrm{g}$ & SD & $\mu g / g$ & SD \\
\hline & $\begin{array}{l}\text { Astaxanthin } \\
\text { C. sapidus }\end{array}$ & $\mu \mathrm{g} \mathrm{g}^{-1}$ & $\begin{array}{l}\text { Astaxanthin } \\
\text { C. bellicosus } \\
\end{array}$ & $\mu \mathrm{g} \mathrm{g}^{-1}$ \\
\hline Ethyl acetate & $16 \mathrm{~d}$ & \pm 0.3 & $22 \mathrm{c}$ & \pm 0.1 \\
\hline Acetone & $39 a^{1}$ & \pm 0.4 & $44 a^{*}$ & \pm 0.2 \\
\hline Cyclohexane & $13 \mathrm{~d}$ & \pm 0.5 & $26 \mathrm{c}$ & \pm 0.5 \\
\hline HAET & $39 \mathrm{a}^{*}$ & \pm 0.1 & $51 \mathrm{a}^{*}$ & \pm 0.4 \\
\hline Isopropyl alcohol & $34 \mathrm{~b}$ & \pm 0.1 & $31 \mathrm{c}$ & \pm 0.3 \\
\hline Hexane & $20 \mathrm{c}$ & \pm 0.2 & $30 \mathrm{~b}$ & \pm 0.1 \\
\hline Heptane & $21 \mathrm{c}$ & \pm 0.2 & $25 \mathrm{c}$ & \pm 0.5 \\
\hline Ethanol & $31 \mathrm{~b}$ & \pm 0.3 & $37 \mathrm{~b}$ & \pm 0.4 \\
\hline
\end{tabular}

\subsection{Identification of astaxanthin type extracted.}

Acetone was one of the most effective solvents to extract astaxanthin in this work; then, the next step was to identify the pigment types extracted by the use of chromatograms obtained by HPLC. Figure 1A shows that unsaponified extracts from shrimp headshells (L. vannamei) were mainly ester astaxanthin (more than $90 \%$ ). On the other hand, in brown crab $(C$. bellicosus) Figure 1B, $64.67 \%$ of total astaxanthin was found in trans astaxanthin (peak 18) with $26.2 \mu \mathrm{g} / \mathrm{g}$, and finally, in blue crabs (C. sapidus) 67.17 of total astaxanthin was found as a trans astaxanthin $(28.43 \mu \mathrm{g} / \mathrm{g}$ ) (Figure 1C). Table 3 shows the astaxanthin types identified in chromatograms, main astaxanthin esters and several geometrical isomers such as all-trans 
astaxanthin, 9-cis astaxanthin, and 13-cis astaxanthin with their specific concentrations. It is important to mention that in carotenoids, the trans configuration has major useful applications than cis isomers. As shown in Figure 1a), the astaxanthin molecule in L. vannamei was found in an esterified form, normally with fatty acids.

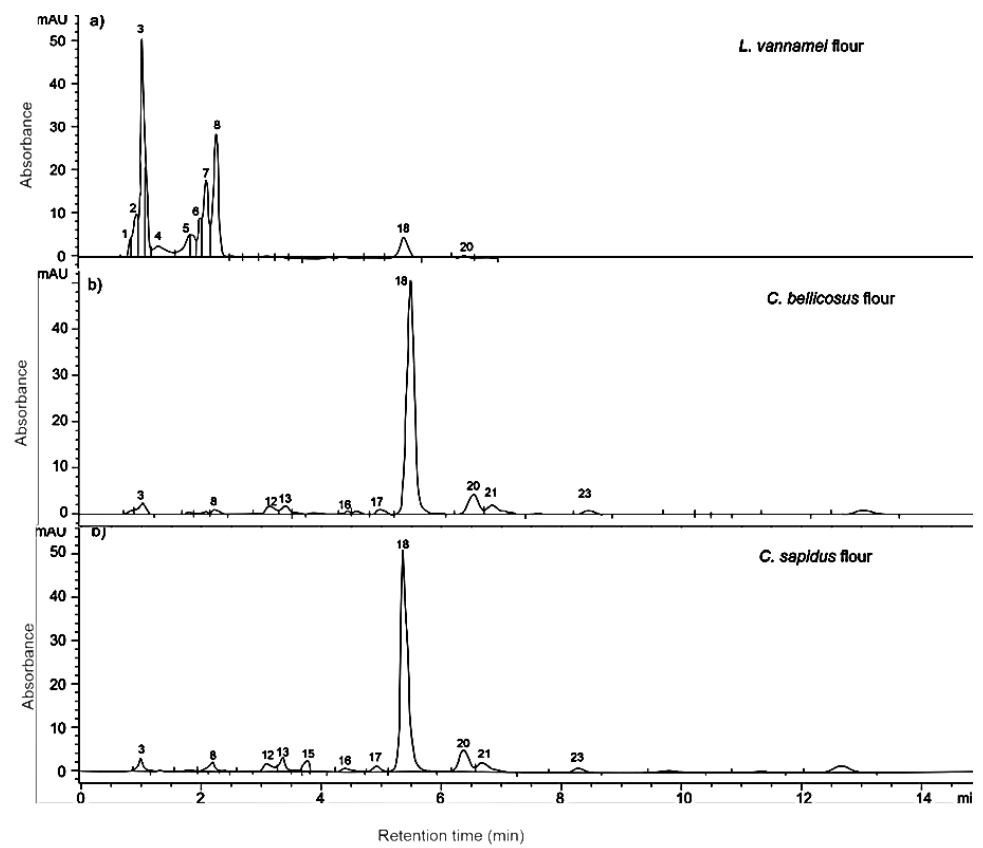

Figure 1. Chromatograms obtained with acetone hydrolysis of flour from: a) L. vannamei, b) C. Sapidus, and c) C. bellicosus.

\subsection{Saponification of acetone hidrosilates from L. vannamei.}

In order to de-esterify astaxanthin esters obtained from shrimp samples, it was necessary to apply a saponification process which under alkaline conditions results in its degradation, the use of $4 \% \mathrm{KOH}$ achieved it, Table 3 show the results of ester separation in $L$. vannamei.

Table 3. Astaxanthin type molecules identified with acetone hydrolysis on HPLC.

\begin{tabular}{|c|c|c|c|c|c|c|}
\hline Peak & Shrimp & $\mu \mathrm{g} / \mathrm{g}$ & Blue crab & $\mu \mathrm{g} / \mathrm{g}$ & Brown crab & $\mu \mathrm{g} / \mathrm{g}$ \\
\hline & L. vannamei & & C. sapidus & & C. bellicosus & \\
\hline 1 & Ast ester & $1.73 \mathrm{~g}$ & ${ }^{1} \mathrm{ND}$ & ND & ND & ND \\
\hline 2 & Ast ester & $6.61 \mathrm{e}$ & ND & ND & ND & ND \\
\hline 3 & Ast ester & $26.22 \mathrm{a}$ & Ast ester & $1.0 \mathrm{c}$ & Ast ester & $0.97 \mathrm{~d}$ \\
\hline 4 & Ast ester & $9.72 \mathrm{~d}$ & ND & ND & ND & ND \\
\hline 5 & Ast ester & $5.60 \mathrm{f}$ & ND & $\mathrm{ND}$ & ND & ND \\
\hline 6 & Ast ester & $5.65 \mathrm{f}$ & Ast ester & $0.1 \mathrm{~d}$ & Ast ester & $0.26 \mathrm{~d}$ \\
\hline 7 & Ast ester & $12.54 \mathrm{c}$ & Ast ester & $0.24 \mathrm{~d}$ & Ast ester & $0.28 \mathrm{~d}$ \\
\hline 8 & Ast ester & $20.40 \mathrm{~b}$ & Ast ester & $0.37 \mathrm{~d}$ & Ast ester & $0.67 \mathrm{~d}$ \\
\hline 10 & ND & ND & ND & ND & ND & ND \\
\hline 11 & Ast isomer & $1.35 \mathrm{~g}$ & ND & ND & Ast isomer & $1.32 \mathrm{c}$ \\
\hline 12 & Ast isomer & $0.94 \mathrm{~h}$ & Ast isomer & $1.23 \mathrm{c}$ & Ast isomer & $1.38 \mathrm{c}$ \\
\hline 13 & ND & ND & Ast isomer & $0.85 \mathrm{~d}$ & ND & ND \\
\hline 14 & ND & ND & ND & ND & ND & ND \\
\hline 15 & Ast isomer & $1.63 \mathrm{~g}$ & Ast isomer & $0.22 \mathrm{~d}$ & Ast isomer & $0.62 \mathrm{~d}$ \\
\hline 16 & ND & ND & Dicis1-ast & $0.29 \mathrm{~d}$ & ND & ND \\
\hline 17 & Dici2-ast & $0.78 \mathrm{~h}$ & Dicis2-ast & $0.29 \mathrm{~d}$ & Dicis2-ast & $0.75 \mathrm{~d}$ \\
\hline 18 & Trans ast & $6.25 \mathrm{e}$ & Trans ast & $26.2 \mathrm{a}$ & Trans ast & $28.43 \mathrm{a}$ \\
\hline 19 & ND & ND & ND & ND & ND & ND \\
\hline 20 & 9cis-ast & $0.81 \mathrm{~h}$ & 9cis-ast & $2.9 \mathrm{~b}$ & 9cis-ast & $3.32 \mathrm{~b}$ \\
\hline 21 & 13 cis-ast & $0.38 \mathrm{~h}$ & 13cis-ast & $1.98 \mathrm{c}$ & 13cis-ast & $1.8 \mathrm{c}$ \\
\hline 22 & ND & ND & Epoxy ast & $0.70 \mathrm{~d}$ & Epoxy ast & $0.85 \mathrm{~d}$ \\
\hline
\end{tabular}

${ }^{1} \mathrm{ND}$ : not detected. 
The main fraction obtained was trans astaxanthin (29.17 \%) (with a specific concentration of $26.7 \mu \mathrm{g} / \mathrm{g}$ (Table 4), and as it happens in C. sapidus and C. bellicosus, also was obtained 9-cis astaxanthin and 13-cis astaxanthin.

Table 4. Astaxanthin type molecules identified with acetone hydrolysis and a posteriori saponification process.

\begin{tabular}{l|l|l} 
Signal & L. vannamei Shrimp & $\boldsymbol{\mu g ~ g ~}^{-1}$ \\
\hline 1 & Ast ester & $1.70 \mathrm{gh}$ \\
\hline 2 & Ast ester & $2.88 \mathrm{fg}$ \\
\hline 3 & Ast ester & $1.21 \mathrm{gh}$ \\
\hline 4 & Ast ester & $1.33 \mathrm{gh}$ \\
\hline 5 & Ast ester & $3.50 \mathrm{ef}$ \\
\hline 6 & Ast ester & $6.26 \mathrm{bc}$ \\
\hline 7 & Ast ester & $6.43 \mathrm{bc}$ \\
\hline 8 & Ast ester & $4.49 \mathrm{de}$ \\
\hline 10 & ${ }^{1}$ ND & ND \\
\hline 11 & ND & ND \\
\hline 12 & Ast isomer & $4.65 \mathrm{de}$ \\
\hline 13 & ND & ND \\
\hline 14 & ND & ND \\
\hline 15 & ND & ND \\
\hline 16 & Ast isomer & $2.62 \mathrm{fg}$ \\
\hline 17 & Dici1-ast & $2.64 \mathrm{fg}$ \\
\hline 18 & Dici2-ast & $3.77 \mathrm{ef}$ \\
\hline 19 & Trans-ast & $26.7 \mathrm{ab}$ \\
\hline 20 & ND & ND \\
\hline 21 & 9cis-ast & $5.75 \mathrm{~cd}$ \\
\hline 22 & $13 c i s-a s t$ & $3.38 \mathrm{ef}$
\end{tabular}

${ }^{1} \mathrm{ND}$ : not detected.

It is well known that astaxanthin can be esterified in one or both hydroxyl groups with some fatty acids such as palmitic, oleic, or linoleic acids [15]. In shrimp wastes, astaxanthin is found mainly in esterified form and normally associated with fatty acids (monoester or diester), and usually, less than $10 \%$ is found in free form. With respect to the astaxanthin quantified in this work, Hu et al. (2019) reported $239 \mu \mathrm{g} / \mathrm{g}$ of astaxanthin extraction from shrimp shells of Procamburus clarkia when was used alcohol at 95\% and ethyl acetate [16]. In this context, Khanafari et al. (2007) reported $23.28 \mu \mathrm{g} / \mathrm{g}$ of astaxanthin and its ethers extracted from shrimp wastes (Penaeus semisulcatus) [17]. Radzali et al. (2014) reported that with ethanol was obtained the highest amount of astaxanthin from Peanus monodon shrimp $(70.26 \mu \mathrm{g} / \mathrm{mg}$ of astaxanthin) but when was used 50\% methanol, the amount of astaxanthin was only $14.57 \mu \mathrm{g} / \mathrm{g}$ of astaxanthin [18]. Dalei and Sahoo (2015) reported the use of acetone as a better solvent to extract astaxanthin from shell shrimp wastes $(48.64 \mathrm{mg} / \mathrm{g}$ ) [19]. Other authors mentioned the use of solvent extraction, for example, some researchers reported the use of n-hexane: isopropyl alcohol (1:1 v/v) for astaxanthin extraction from shrimp waste (Fanaeus indicus) with 43.9 $\mu \mathrm{g} / \mathrm{g}$; acetone for pigment extraction from Penaeus indicus as a better choice with $40.6 \mu \mathrm{g} / \mathrm{g}$ and n-hexane isopropyl alcohol (6:4 v/v) from Farfantepenaeus paulensis with $53 \mu \mathrm{g} / \mathrm{g}$. On the other hand, Yoon et al. (2012) reported a yield of $17.8 \mu \mathrm{g} / \mathrm{g}$ of astaxanthin extracted when ethanol was used [20]. As we can see, the amount of astaxanthin extracted on shrimp, blue crab, and brown crab with different solvents used in this work fall in the range reported by several authors. Khanafari et al. (2007) reported the extraction of astaxanthin esters from shrimp wastes Penaeus semisulcatus when was used diethylamine, hexane, acetone, and ethyl acetate as an organic solvent [17]. In C. sapidus (blue crab), Suganya and Asheeba (2015) reported the extraction of monoesters and diesters when astaxanthin was extracted with isopropanol; monoesters when was extracted with DMSO acetone, but its molecules were absent when was used acetone as a solvent [21]. Coral-Hinostroza and Bjerkeng (2002), 
reported in Pleuroncodes planipes diesters; C14:0 (5-9\%), C16:0 (17-30\%), C20:0 (0-23\%), $\mathrm{C} 16(12-15 \%)$ and $\mathrm{C} 18: 1(15-24 \%)$ while C20:5 was the most predominant fraction (47\%) [22]. Breithaupt (2004) identified astaxanthin esters in extracts of Pandulus borealis: astaxanthin-C16:0, astaxanthin-C16:0/C16:0, and free astaxanthin [23]. The method to remove it is by a saponification process; however, the de-esterification of natural astaxanthin esters is rarely published. In this context, the same author reported the highest efficiency of cholesterol esterase to remove astaxanthin's fatty acids than the saponification process with $\mathrm{NaOH}$. The effectiveness depends basically on time. The effectiveness depends basically on time between 60 to 90 minutes. In this work, all-trans astaxanthin was the predominant isomer, followed by astaxanthin isomers, dici1, dici2, 9-cis, and 13-cis astaxanthin.

\section{Conclusions}

Fresh wastes of Mexican headshell shrimp (Litopenaeus vannamei), blue crab (Callinectes bellicosus), and Mexican brown crab (Callinectes sapidus) exoskeletons were autoclaved, dried, and grounded at a particle size of $150 \mu \mathrm{m}$. Macerated samples were diluted to ethyl acetate, acetone, cyclohexane, isopropyl alcohol, hexane, heptane, and a combination of hexane-acetone-ethanol-toluene solvents. High-Performance Liquid Chromatography analysis determined the astaxanthin amount in every organic solvent extract. Acetone was the most efficient solvent; the mixture of hexane-acetone-ethanol-toluene resulted in an idoneus solvent used on crab exoskeletons.

\section{Funding}

This research received no external funding.

\section{Acknowledgments}

This research was financed by the enterprise Mexi Food S.A de C.V (crab processing plant) and CONACyT (Consejo Nacional de Ciencia y Tecnología, Mexico). Thanks are extended to Industrias Vepinsa S.A de C.V. Sinaloa, Mexico for the chromatographic analysis performance.

\section{Conflicts of Interest}

The authors declare no conflict of interest.

\section{References}

1. FAO. The State of World Fisheries and Aquaculture 2020. Sustainability in action. Rome. 2020; https://doi.org/10.4060/ca9229en.

2. $\quad$ Santos, V.P.; Marques, N.S.S.; Maia, P.C.S.V.; Barbosa, M.A.L.; Oliveira, L.F.; de Campos-Takaki, G.M.; Seafood waste as attractive source of chitin and chitosan production and their applications. Int J Mol Sci 2020, 21, 1-17, https://doi.org/10.3390/ijms21124290.

3. Yadav, M.; Goswami, P.; Paritosh, K.; Kumar, M.; Pareek, N.; Vivekanand, V. Seafood waste: a source for preparation of commercially employable chitin/chitosan materials. Bioresour Bioprocessing 2019, 6, 1-20, https://doi.org/10.1186/s40643-019-0243-y.

4. Doan, C.T.; Tran, T.N.; Nguyen, V.B.; Vo, T.P.K.; Nguyen, A.D.; Wang, S.L. Chitin extraction from shrimp waste by liquid fermentation using alkaline protease-producing strain, Brevibacillus parabrevis. Int J of Biol Macromol 2019, 131, 706-715, https://doi.org/10.1016/j.ijbiomac.2019.03.117.

5. Maoka, T. Carotenoids as natural functional pigments. $J$ Nat Med 2020, 74, 1-16, https://doi.org/10.1007/s11418-019-01364-x. 
6. Komolka, K.; Bochert, R.; Franz, G.P.; Kaya, Y.; Pfuhl, R.; Grunow, B. Determination and comparison of physical meat quality parameters of percidae and salmonidae in aquaculture. Foods 2020, 9, 1-13, https://doi.org/10.3390/foods9040388.

7. Pereira, C.P.M.; Remondi, S.C.; Rodrigues, V.A.; Prado, P.S.; Name, J.J. Antioxidant and anti-inflammatory mechanisms of action of astaxanthin in cardiovascular diseases (Review). Int J Mol Med 2021, 47, 37-48. https://doi.org/10.3892/ijmm.2020.4783.

8. Bampidis, V.; Azimonti, A.; Bastos, M.L.; Christensen, H.; Dusemund, B.; Kouba, M.; Durjava, M.K.; López-Alonso, M.; López, P.S.; Marcon, F.; Mayo, B.; Pechová, A.; Petkova, M.; Ramos, F.; Sanz, Y.; Villa, R.E.; Woutersen, R.; Bories, G.; Brantom, P.; Renshaw, D.; Schlatter, J.R.; Ackerl, R.; Holczknecht, O.; Steinkellner, H.; Vettori, M.V.; Gropp, J. Safety and efficacy of astaxanthin-dimethyldisuccinate (Carophyll ${ }^{\circledR}$ Stay-Pink 10\%-CWS) for salmonids, crustaceans and other fish. EFSA Journal 2019, 17, 1-42.

9. Nguyen, T.T.; Heimann, K.; Zhang, W. Protein recovery from under utilised marine bioresources for product development with nutraceutical and pharmaceutical bioactivities. Mar Drugs. 2020, 18, 1-48. https://doi.org/10.3390/md18080391.

10. Ahmadkelayeh, S.; Hawboldt, K. Extraction of lipids and astaxanthin from crustacean by-products: A review on supercritical $\mathrm{CO}_{2}$ extraction. Trends Food Sci Technol 2020, 103, 94-108, https://doi.org/10.1016/j.tifs.2020.07.016.

11. Routray, W.; Dave, D.; Cheema, S.K.; Ramakrishnan, V.V.; Pohling, J. Biorefinery approach and environment-friendly extraction for sustainable production of astaxanthin from marine wastes. Crit Rev Biotechnol 2019, 39, 469-488, https://doi.org/10.1080/07388551.2019.1573798.

12. Hu, J.; Lu, W.; Lu, M.; Wang, Y.; Ding, R.; Wang, L. Extraction and purification of astaxanthin from shrimp shells and the effects of different treatments on its content. Rev Bras Farmacog 2019, 29, 24-29, https://doi.org/10.1016/j.bjp.2018.11.004.

13. Zuharlida, T.H.Z.; Andrade, L.M.; Charalampopoulos, D.; Chatzifragkou, A. Optimised production and extraction of astaxanthin from the yeast Xanthophyllomyces dendrorhous. Microorganisms 2020, 8, 1-18, https://doi.org/10.3390/microorganisms8030430.

14. Du, X.; Wang, X.; Bai, M.; Liu, S.; Huang, G.; Zhang, Q.; Ni, H.; Chen.F. A quantitative analysis model established to determine the concentration of each source in mixed astaxanthin from different sources. Molecules. 2020, 25, 1-10, https://doi.org/10.3390/molecules25030628.

15. Panintingjati, B.T.H.; Limantara, L.; Setiyono, E. Structures of astaxanthin and their consequences for therapeutic application. Int J Food Sci 2020, 1-16, https://doi.org/10.1155/2020/2156582.

16. Hu, J.; Lu, W.; Wang, Y.; Ding, R.; Wang, L. Extraction and purification of astaxanthin from shrimp shells and the effects of different treatment on its content. Rev Bras Farmacogn 2019, 29, 24-29, https://doi.org/10.1016/j.bjp.2018.11.004.

17. El-Bialy, H.A.; El-Khalek, H.H.A. A comparative study on astaxanthin recovery from shrimp wastes using lactic fermentation and green solvents: an applied model on minced Tilapia. J Radiat Res Appl Sc 2020, 13, 609-620, https://doi.org/10.1080/16878507.2020.1789388.

18. Radzali, S.A.; Baharin, B.S.; Oyhman, M.M.; Rahman, R.A. Co-solvent selection for supercritical fluid extraction of astaxanthin and other carotenoids from Penaues monodon waste. J Oleo Sci 2014, 63, 769-777, https://doi.org/10.5650/jos.ess 13184 .

19. Solva, A.K.N.; Rddrogues, B.D.; Solva, L.H.M.; Rddrogues, A.M.C. Drying and extraction of astaxanthin from pink shrimp waste (Farfantepenaeus subtilis): the applicability of spouted beds. Food Sci Technol 2018, 38, 454-461, https://doi.org/10.1590/fst.31316.

20. Yoon, C.H.; Bok, H.S.; Choi, D.K.; Row, K.H. Optimization condition of astaxanthin extract from shrimp waste response surface methodology. Korean Chem Eng Res 2012, 50, 545-550, https://doi.org/10.9713/kcer.2012.50.3.545.

21. Laith, A.A.; Ambak, M.; Abol-Munafi A.B.; Nurhafizah, W.W.I.; Najiah, M. Metabolomic analysis of marine and mud crabs based on antibacterial activity. Aquac Rep 2017, 7, 7-15, https://doi.org/10.1016/j.aqrep.2017.05.002.

22. Coral-Hinostroza, G.N.; Bjerkeng, B. Astaxanthin from the red crab lasgostilla (Pleuroncodes planipes): optical R/S isomers and fatty acid moieties of astaxanthin esters. Comp. Biochem Physiol 2002, 133, 437444, https://doi.org/10.1016/s1096-4959(02)00186-0.

23. Breithaupt, D.E.J. Identification and quantification of astaxanthin esters in shrimp (Pandalus borealis) and in a microalga (Haematococcus pluvialis) by liquid chromatography-mass spectrometry using negative ion atmospheric pressure chemical ionization. Agric Food Chem 2004, 16, 3870-3875, https://doi.org/10.1021/jf049780b. 